\title{
KNOWLEDGE ABOUT CERVICAL CANCER AMONG MARRIED WOMEN ATTENDING PRIMARY HEALTH CARE CENTERS IN DUHOK CITY
}

\author{
IMAN YOUSIF ABDULMALEK, MBCHB, FICMS * \\ KAWTHER MAHMOOD KALARY, BSC, MSC (Maternity Nursing)**
}

\section{Submitted 7 October 2019; accepted 11 January 2020}

\begin{abstract}
Background: Despite the consideration that cervical cancer is a preventable cancer, it still known as one of the most common cancers among women worldwide. It kills about 270,000 women every year, and $85 \%$ of these deaths occur in less-developed regions. Cervical cancer is an important public health problem in developing countries due to lack of knowledge about the disease and its risk factors with poor access to preventive services. Early detection of it is performed by a medical screening procedure Pap smear.

Objectives: The present study aimed to assess the knowledge about cervical cancer and its association with the socio-demographic characteristics among married women attending primary health care centers (PHCCs) in Duhok city.

Materials and Methods: A cross sectional descriptive study was conducted among 400 women in the PHCCs from 7th of April- 30thof May 2015, through direct interview with them by using a structured questionnaire to gather the data related to the knowledge concerning cervical cancer.

Results: Among all women who were interviewed, 57.2\% heard about cervical cancer and only $(25 \%)$ of them had good knowledge about it, while $35.9 \%$ heard of Pap smear and the good knowledge in $7.3 \%$, the main reason for doing this test was health provider's advice. The majority of women $71.6 \%$ received information about cervical cancer from their friends, or family members among those who had a family history, but only $6.5 \%$ of them reported that the internet or T.V as a source of information. Most of them $96.5 \%$ did not have a family history of this cancer and less than half of them $48.8 \%$ were of medium socioeconomic status. The impact of smoking as a cause was $87.3 \%$, while $43.2 \%$ considered the early age of marriage was the risk factor. There was a statistically significant association between the women's knowledge about cervical cancer and their occupations $(P=0.03)$.

Conclusions: The majority of women had low knowledge about cervical cancer and Pap smear. Effective media and providing health education are required to improve the level of awareness toward them.
\end{abstract}

Keywords: Knowledge, Cervical Cancer, Pap smear.

Duhok Med J 2020; 14 (1): 92-105.

C

ervical Cancer (CC) is a fatal disease

once it reaches its invasive stages, but it is the only preventable cancer among all the female genital tract cancers when it is detected in its pre-malignant stage ${ }^{1}$. This is probably why a lot of researches have been carried out concerning this cancer since it can save thousands of lives which unnecessarily die each year. Strong evidence shows that the progression of cervical cancer into its later stages can be prevented through screening and treatment of premalignant lesions. In developed countries, due to effective screening programs, through the use of Papanicolaou (Pap) smear test for identifying premalignant changes in the cervix, so the incidence of cervical cancer has been controlled $^{2}$. The prevalence of it is higher in less-developed countries due to the lack

* Assis. Prof., Department of Gyneco. \& Obstetrics, Collage ofMedicine, University of Duhok, Kurdistan Region, Iraq. 
of information toward it, no idea about the vaccination of HPV, and no screening program for early detection and treatment of premalignant cases, it is estimated that only $5 \%$ of women are screened appropriately for cervical cancer ${ }^{3}$.

The human papillomavirus (HPV) is an important cause of cervical cancer, which is the fourth most common cancer in women, with an estimated 266,000 deaths and 528,000 new cases in 2012. A large majority around $85 \%$ of the global burden occurs in the less developed regions, where it accounts for almost $12 \%$ of all female cancers and screening services are lacking or are poorly accessible ${ }^{4}$.

HPV is transmitted sexually, so women who have had multiple partners or a high risk partner, began having intercourse at an early age, smoke and have used birth control pills for more than 5 years are more at risk for HPV infection than others. Not every woman infected with HPV will get $\mathrm{CC}^{5}$. Additional risk factors include: sexually transmitted infections (STIs), immune-suppression, and a diet low in fruits, vegetables and vitamins, overweight, multiple full pregnancy, poverty and mothers used diethylstilbestrol $(\mathrm{DES})^{6}$.

HPV vaccines may prevent infections through certain types of HPV and provide the best protection for girls and boys who have received all three vaccine doses and have time to improve their immune response before being sexually active with another person 7 .

Mortality rate varies 18 -fold between the different regions of the world, with rates ranging from less than 2 per 100,000 in Western Asia, Western Europe, and Australia/New Zealand, to more than 20 per 100,000 in Melanesia, Middle and Eastern Africa ${ }^{8}$.

Local situation: Although the incidence of cervical cancer in Iraq is relatively low, as in most other Islamic countries, yet most of the cases usually present in advanced stages with poor prospects of cure ${ }^{9}$, the current estimates indicate that 311 women are diagnosed with cervical cancer and 212 die from the disease every year. Cervical cancer ranked as the seventh most common cancer among women aged between 15 and 44 years $^{10}$. There were no studies related to the knowledge about CC and its risks in Duhok city. While there were some studies conducted in Iraqi cities like Baghdad and Diyala related to CC and its screening ${ }^{10,11,12}$.

The percentage of new cases and mortality rate of $\mathrm{CC}$ in Duhok city have increased gradually, but it is a very low percentage when compared to other developing countries, as many women are still presenting late with advanced disease due to lack of knowledge about the CC and PS. According to Ministry of Health Statistics from 2010-2014, there was an increase in the new cases and in the death rate from $3.7 / 1000$ population in 2012 to $4.2 / 1000$ population in 2014, because there was no screening program and may be increasing the risk factors that are related to it 13. A more effective educational program is needed to educate Iraqi women about CC and screening tests, including PS.

So this study aimed to assess the knowledge about $\mathrm{CC}$ and the most important risk factors of it, and its association with the socio-demographic characteristics among married women attending primary health care centers (PHCCs) in Duhok city. 


\section{METHODS}

Design of the study and Target populations: A cross sectional descriptive study was done among married women for assessing their knowledge regarding cervical cancer in Duhok city. The subject of the present study included all married women aged 21-65 years who attended primary health care centers (PHCCs) in Duhok city, there are 14 PHCCs. Some of these centers were included in this study; they were selected using a simple random sampling. Most of the women from all socioeconomic status attend these centers for routine vaccinations, child and maternal health care, dental care, laboratory investigations, antenatal care, family planning and outpatient department. These services are found in all of these PHCCs.

The non-probability sampling was applied to 400 married women who attended the PHCCs in Duhok city, 133 women from each of Behdinan center and Shahidan center, and 134 women from Khabat center. Inclusion criteria included women who were: married; aged from 21-65 years; attending to the PHCCs for any reason during the time of data collection; willing to participate in the study; able to speak clearly in Kurdish or Arabic. The Exclusions criteria included women who were: Health care worker (medical staff) and disagree to participate (the nonresponse rate was $3 \%$ ). The permission was taken from the Directorate General of Health in Duhok city. Data were gathered by the researcher through direct interview with women by using a structure validated questionnaire at any area in the PHCCs where the women were available. Before gathering the information, oral consent was taken from the women for participation in the study before starting data collection. The questionnaire interview was prepared in English language, but it was translated into Kurdish or Arabic language to be understood by women. The data were collected five days during the time working of PHCC; within three hours/day about 10-13 women were interviewed. The time of interviewing with each woman took approximately 10-20 minutes.

The questionnaire consists of two parts: The first part aimed to collect women's socioeconomic and demographic characteristics, including (age, gravida, residence, occupation, level of education, and family history of $\mathrm{CC}$, and socioeconomic status (SES). The second part was to assess the knowledge about CC. There were 19 items related to knowledge toward it, including nine items about the risk factors that lead to $\mathrm{CC}$, and ten items for general information about CC.

Data analysis: Assessment of knowledge scores toward CC: Regarding the 10 questions toward the knowledge about $\mathrm{CC}$ were putting it on Modified Bloom's cut off, which was adopted from Nahida's KAP study in $2013^{14}$. The questions had a value of 1 or 0 (correct response had a value of ' 1 ' and wrong or don't know response had a value of ' 0 '). Therefore, the scores with their respective knowledge levels were: low levels (less than 50\%), Moderate levels (50-79\%) and good levels (80-100\%).

About the assessment of SES scores: The level of SES were persuaded by the participants by asking them to estimate their level of living. The levels were classified into three classes: (Low class), (Medium class), and (High class).

Statistical analysis: The data were entered and analyzed by using the statistical 
package for social sciences (SPSS version 19), the Categorical variables are presented as numbers, frequency or percentages. The inferential data analysis approach (Chi square test and Fisher's exact test, Chi square test of association was used to compare the proportions when the expected count of more than $20 \%$ of the cells of the table, if it was less than $5 \%$, Fisher's exact test was used), while the $\mathrm{P}$ value of $\leq 0.05$ was considered statistically significant.

\section{RESULTS}

Table 1 shows the socio- demographic characteristics of women. Among the 400 women from three primary health care centers (PHCCs) in Duhok city, the mean age (+SD) was $33.54+8.69$ years, the majority of women $41.3 \%$ aged between $30-39$ years old, $61.4 \%$ of them had 1-4 children, and most of them 97\% were living in urban areas. More than three quarters $80.5 \%$ were housewives and unemployed; $39.3 \%$ as primary school graduation, while very low percentage of women $5.3 \%$ had university \& high level of education. The higher number of them 96.5\% did not have a family history of cervical cancer; less than half of the families $48.8 \%$ were of medium socioeconomic status (SES) and only $10.4 \%$ of a high SES. Among 400 women who were interviewed, only 229 of them heard about cervical cancer, and 144 of women heard about PS as in Table 2.

\begin{tabular}{lcc}
\hline \multicolumn{2}{c}{ Table 1: Distribution of women's age, gravida, residency, occupations, levels of education } \\
\hline Socio-Demographic Characteristics & No. & Percentage (\%) \\
\hline Age (years) & 143 & $(35.8)$ \\
$<30$ & 165 & $(41.3)$ \\
$30-39$ & 65 & $(16.3)$ \\
$40-49$ & 27 & $(6.8)$ \\
$\geq 50$ & & \\
Gravid & 21 & $(5.3)$ \\
Nulliparous & 246 & $(61.4)$ \\
$1-4$ & 133 & $(33.3)$ \\
$5+$ & & \\
Residency & 388 & $(97.0)$ \\
Urban & 12 & $(3.0)$ \\
Rural & & \\
Occupation & 322 & $(80.5)$ \\
Housewife and unemployed & 75 & $(18.8)$ \\
Manual worker \& employed & 3 & $(0.7)$ \\
High rank occupations & & \\
Level of education & & $(19.7)$ \\
Illiterate & 79 & $(39.3)$ \\
Primary School Graduate & 157 & $(35.7)$ \\
Secondary School Graduate & 143 & $(5.3)$ \\
University \& High Level of Education & & \\
Family history of CC & 21 & $(3.5)$ \\
Yes & & $(96.5)$ \\
No & 14 & \\
Socioeconomic s tatus (SES) & 386 & \\
\end{tabular}




\begin{tabular}{lcc}
\hline Duhok Medical Journal & Volume 14, Issue 1,2020 \\
\hline Socio-Demographic Characteristics & No. & Percentage (\%) \\
\hline Low clas s & 163 & $(40.8)$ \\
Medium clas s & 195 & $(48.8)$ \\
High clas s & 42 & $(10.4)$ \\
\hline Total & $\mathbf{4 0 0}$ & $\mathbf{( 1 0 0 )}$ \\
\hline
\end{tabular}

\begin{tabular}{lcccccc}
\hline \multicolumn{1}{c}{ Table 2: Knowledge toward CC and PS } & \\
\hline \multirow{2}{*}{ Knowledge } & \multicolumn{3}{c}{ Yes } & \multicolumn{2}{c}{ No } & Total \\
\cline { 2 - 7 } & No. & $(\boldsymbol{\%})$ & No. & $\mathbf{( \% )}$ & No. & $(\boldsymbol{\%})$ \\
\hline Had heard about CC & 229 & $(57.2)$ & 171 & $(42.8)$ & 400 & $(100)$ \\
Had heard about Pap test & 144 & $(36.0)$ & 256 & $(64.0)$ & 400 & $(100)$ \\
\hline
\end{tabular}

Knowledge about the most important risk factors of the $\mathrm{CC}$

In $87.3 \%$ of 229 had a good overview of the impact of smoking as a cause of $\mathrm{CC}$, while $43.2 \%$ considered the early age of marriage as the risk that lead to $\mathrm{CC}$; on the other hand, more than half of them $56.8 \%$ reported that early age of marriage $>18$ is not considered a risk, as shown in Table 3.

\begin{tabular}{|c|c|c|}
\hline Risk Factors & Yes & Percentage $(n=229) \%$ \\
\hline Sexually transmitted diseases & 178 & (77.7) \\
\hline Use of contraception & 139 & $(60.7)$ \\
\hline Early age of marriage & 99 & $(43.2)$ \\
\hline Multiple partners & 186 & $(81.2)$ \\
\hline Human papillomavirus & 20 & (6.6) \\
\hline Having many child birth & 102 & (34.1) \\
\hline Do not know & 80 & $(26.7)$ \\
\hline Family History & 168 & $(73.4)$ \\
\hline Smoking & 200 & (87.3) \\
\hline
\end{tabular}

Source of information about CC

Only 229 women had ever heard of CC and the majority of women $71.6 \%$ received information about $\mathrm{CC}$ from their friends, or family member among those who had a family history about CC, $21.9 \%$ from physician or nurses, and only $6.5 \%$ of them reported that the internet or T.V as a source of information, as noted in the Figure 1.

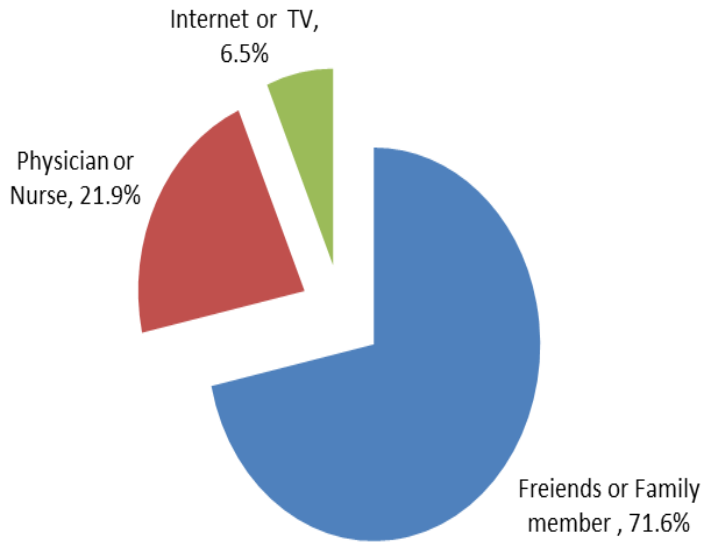

Figure 1: Distribution of women' information s ource related to $\mathrm{CC}$ 
Distribution of women's knowledge levels regarding $\mathrm{CC}$

Regarding the level of knowledge about $\mathrm{CC}$, the greater number of women, $44.5 \%$ had a low level of knowledge, $30.5 \%$ of women had a medium level of knowledge, and only one quarter of women $25.0 \%$ had a good level of knowledge.

Distribution of women' knowledge about $\mathrm{CC}$
Regarding women's information about CC. Most of them $86.5 \%$ considered that the genitourinary infection increase the risk of $\mathrm{CC} ; 57.2 \%$ thought the pelvic pain is one of CC symptoms, while $31.9 \%$ didn't know whether it was a symptom, $37.1 \%$ reported spotting between menses is not associated with the development of this cancer, and $10.0 \%$ reported CC is free of sings in the early stage as shown in Table 4.

\begin{tabular}{|c|c|c|c|c|c|c|}
\hline \multirow{2}{*}{ Statements } & \multicolumn{2}{|c|}{ Yes } & \multicolumn{2}{|c|}{ No } & \multicolumn{2}{|c|}{ I don't know } \\
\hline & No. & $(\%)$ & No. & $(\%)$ & No. & $(\%)$ \\
\hline $\begin{array}{l}\text { Is cervical cancer one of the most common } \\
\text { cancers among women? }\end{array}$ & 151 & $(65.9)$ & 66 & $(28.8)$ & 12 & $(5.2)$ \\
\hline Is cervical cancer preventable? & 132 & $(57.6)$ & 74 & $(32.3)$ & 23 & $(10.0)$ \\
\hline Is cervical cancer is a fatal disease & 152 & $(66.4)$ & 35 & $(15.3)$ & 42 & $(18.3)$ \\
\hline Is cervical cancer curable? & 109 & $(47.6)$ & 84 & $(36.7)$ & 36 & $(15.7)$ \\
\hline $\begin{array}{l}\text { Does a genitourinary infection increase the risk } \\
\text { of cervical cancer among women? }\end{array}$ & 198 & $(86.5)$ & 17 & (7.4) & 14 & $(6.1)$ \\
\hline $\begin{array}{l}\text { Is spotting between menstrual periods may be a } \\
\text { symptom of cervical cancer? }\end{array}$ & 84 & $(36.7)$ & 85 & $(37.1)$ & 60 & $(26.2)$ \\
\hline $\begin{array}{l}\text { Is bleeding and spotting after menopause may be } \\
\text { linked with cervical cancer? }\end{array}$ & 109 & $(47.6)$ & 49 & $(21.4)$ & 71 & $(31.0)$ \\
\hline $\begin{array}{l}\text { May cervical cancer be without sign in early } \\
\text { stages? }\end{array}$ & 192 & $(83.8)$ & 23 & $(10.0)$ & 14 & $(6.1)$ \\
\hline Is pelvic pain one of cervical cancer symptoms? & 131 & $(57.2)$ & 25 & $(10.9)$ & 73 & $(31.9)$ \\
\hline $\begin{array}{l}\text { Is the cervical cancer can be detected early by } \\
\text { screening }\end{array}$ & 164 & $(71.6)$ & 22 & (9.6) & 43 & $(18.8)$ \\
\hline
\end{tabular}

Association of women's knowledge levels with their socio-demographic characteristics. There was a statistically significant association between the women's knowledge about CC and their socio-demographic characteristics apart of residency, as shown in Table 5. 


\begin{tabular}{|c|c|c|c|c|c|c|c|c|c|}
\hline \multicolumn{7}{|c|}{ Duhok Medical Journal } & \multicolumn{3}{|c|}{ Volume 14, Issue 1,2020} \\
\hline \multicolumn{10}{|c|}{$\begin{array}{l}\text { Table 5: Association between women's knowledge toward CC and Socio-Demographic Characteristics } \\
\text { (Total } 400 \text { women). }\end{array}$} \\
\hline \multirow{3}{*}{$\begin{array}{c}\text { Socio- } \\
\text { Demographic } \\
\text { Characteristics }\end{array}$} & \multicolumn{6}{|c|}{ Knowledge level } & \multirow{2}{*}{\multicolumn{2}{|c|}{ Total }} & \multirow{3}{*}{ P-value } \\
\hline & \multicolumn{2}{|c|}{ Low } & \multicolumn{2}{|c|}{ Medium } & \multicolumn{2}{|c|}{ Good } & & & \\
\hline & No. & $(\%)$ & No. & $(\%)$ & No. & $(\%)$ & No. & $(\%)$ & \\
\hline \multicolumn{9}{|l|}{ Age (years) } & \multirow{5}{*}{$* 0.013$} \\
\hline$<30$ & 77 & $(55.0)$ & 35 & $(25.0)$ & 28 & $(20.0)$ & 140 & $(100)$ & \\
\hline $30-39$ & 62 & $(37.8)$ & 58 & $(35.3)$ & 44 & $(26.8)$ & 164 & $(100)$ & \\
\hline $40-49$ & 24 & $(36.5)$ & 18 & $(27.2)$ & 24 & $(36.3)$ & 66 & $(100)$ & \\
\hline$\geq 50$ & 15 & $(50.0)$ & 11 & $(36.6)$ & 4 & (13.4) & 30 & $(100)$ & \\
\hline \multicolumn{9}{|l|}{ Gravid } & \multirow{4}{*}{$*<0.001$} \\
\hline Nullipara & 9 & $(22.5)$ & 6 & $(15.0)$ & 25 & $(62.5)$ & 40 & $(100)$ & \\
\hline $1-4$ & 104 & $(46.4)$ & 72 & $(26.0)$ & 48 & $(7.3)$ & 224 & $(100)$ & \\
\hline$\geq 5$ & 65 & $(47.8)$ & 44 & $(24.1)$ & 27 & (8.3) & 136 & $(100)$ & \\
\hline \multicolumn{9}{|l|}{ Residency } & \multirow{3}{*}{$\dagger 0.671$} \\
\hline Urban & 172 & $(44.5)$ & 117 & $(30.2)$ & 98 & $(25.3)$ & 387 & $(100)$ & \\
\hline Rural & 6 & $(46.2)$ & 5 & $(38.5)$ & 2 & $(15.3)$ & 13 & $(100)$ & \\
\hline \multicolumn{9}{|c|}{ Level of education } & \multirow{5}{*}{$* 0.004$} \\
\hline Illiterate & 36 & $(48.6)$ & 29 & $(39.2)$ & 9 & $(12.2)$ & 74 & $(100)$ & \\
\hline $\begin{array}{l}\text { Primary School } \\
\text { Graduate }\end{array}$ & 73 & $(47.0)$ & 36 & $(23.3)$ & 46 & $(29.7)$ & 155 & $(100)$ & \\
\hline $\begin{array}{l}\text { Secondary School } \\
\text { Graduate }\end{array}$ & 62 & $(41.9)$ & 52 & $(35.1)$ & 34 & $(23.0)$ & 148 & $(100)$ & \\
\hline $\begin{array}{l}\text { University \& High } \\
\text { Level of Education }\end{array}$ & 7 & $(30.4)$ & 5 & $(21.7)$ & 11 & $(30.4)$ & 23 & $(100)$ & \\
\hline \multicolumn{9}{|c|}{ Family History of CC } & \multirow{3}{*}{$*<0.001$} \\
\hline Yes & 3 & $(12.0)$ & 16 & $(64.0)$ & 6 & $(24.0)$ & 25 & $(100)$ & \\
\hline No & 175 & $(46.7)$ & 106 & $(28.3)$ & 94 & $(25.0)$ & 375 & $(100)$ & \\
\hline \multicolumn{9}{|c|}{ Socioeconomic status } & \multirow{4}{*}{$*<0.001$} \\
\hline Low class & 88 & $(56.0)$ & 44 & $(28.0)$ & 25 & $(16.0)$ & 157 & $(100)$ & \\
\hline Medium class & 80 & $(42.1)$ & 59 & $(31.0)$ & 51 & $(26.9)$ & 190 & $(100)$ & \\
\hline High class & 10 & $(18.8)$ & 19 & $(35.9)$ & 24 & $(45.3)$ & 53 & $(100)$ & \\
\hline \multicolumn{9}{|l|}{ Occupation } & \multirow{5}{*}{$\dagger<0.001$} \\
\hline $\begin{array}{l}\text { Housewife and } \\
\text { Unemployed }\end{array}$ & 169 & $(52.4)$ & 91 & $(28.3)$ & 62 & $(19.3)$ & 322 & $(100)$ & \\
\hline $\begin{array}{l}\text { Manual Worker \& } \\
\text { Employee }\end{array}$ & 8 & $(10.7)$ & 29 & $(38.7)$ & 38 & $(50.6)$ & 75 & (100) & \\
\hline $\begin{array}{l}\text { High rank } \\
\text { occupations }\end{array}$ & 1 & $(33.3)$ & 2 & $(66.7)$ & 0 & $(0.0)$ & 3 & (100) & \\
\hline Total & 178 & (44.5) & 122 & $(30.5)$ & 100 & (25) & 400 & (100) & \\
\hline
\end{tabular}




\section{DISCUSSION}

Cervical cancer is one of the most common cancers in women worldwide. It ranks as the $7^{\text {th }}$ most frequent cancer among Iraqi women and it is the 2nd most common cancer in Malaysia ${ }^{15}$.

In this present study, $57.2 \%$ of women heard about $\mathrm{CC}$, similar to this finding $57.4 \%$ was reported among Iraqi women residing outside Iraq in Malaysia ${ }^{15}$. This was less than that $60.9 \%$ reported in another study conducted among female students of a tertiary institution in South Eastern Nigeria ${ }^{16}$, and $76.9 \%$ reported in a study done among Kuwaiti women ${ }^{17}$. But it is higher than $42.9 \%$ amongst women who were visiting tertiary centre in Kathmandu, Nepal ${ }^{18}$, $16 \%$ reported in Kolkata, India of sample among women attending a women's health clinic $^{19}$, and $74 \%$ of study women living in KampongSpeu, Cambodia, had ever heard about cervical cancer ${ }^{20}$.

These different results of the studies may be due to their conduction among women with different levels of education. So the majority of women in the present study were illiterate or primary school graduates, compared to other studies conducted on women who had a secondary or higher level of education. Although the rates of the disease have been reduced in most of the developed countries in the last thirty years as a result of appropriate screening and advanced treatment programs in contrast to developing countries where the incidence has increased or remained unchanged. In Iraq, the aim is to elevate the level of awareness and promoting screening program ${ }^{21}$.

This study shows that the majority of women $44.5 \%$ had low level of knowledge about $\mathrm{CC}$, this was similar to what was reported in 2008 in a study among patients in a tertiary centre in Southeastern Nigeria), and in 2013 in a study done among Iraqi immigrant women living in Malaysia ${ }^{15,16}$, and it was much better than $81.9 \%$ that reported in a study among women in India ${ }^{22}$. Although it was less than $52.3 \%$ in study among Married Kuwaiti women ${ }^{17}, 55.7 \%$ of midwives in Côte d'Ivoire, West Africa ${ }^{23}$, and $93.7 \%$ of women who had appropriate with very good knowledge in study among women over 20 years in Istanbul, Turkey ${ }^{24}$. So these findings showed that the level of knowledge about CC screening remains low, because the public education about cervical cancer is low too.

Regarding the percentages of women's knowledge about the risk factors which lead to $\mathrm{CC}$ in this study, the sexually transmitted diseases are $77.7 \%$, smoking $87.3 \%$, multiple partners $81.2 \%$, early age of marriage $43.2 \%$, they were higher than the percentages in a study conducted among women visiting primary health care in Qatar ${ }^{25}$, but it wasn't like another study in Abidjan ,West Africa by (Tchounga, et al. 2014) ${ }^{23}$, which was recorded the highest percentages as multiple sexual partners $85.5 \%$ and early sexual intercourse $80.1 \%$ were the main risk causes. This difference may be due to the social customs of early marriage. In another study in Cambodia, $47 \%$ and $2 \%$ of women reported multiple sexual partners and HPV infection, respectively, as the most important risk factors of cervical cancer ${ }^{20}$.

In this study, the majority of women $87.3 \%$ reported that smoking is the first risk factors behind developing $\mathrm{CC}$, less than $57.58 \%$, this result was reported in 
Iraq $^{26}$ and $7 \%$ in Pakistan ${ }^{27}$. This difference between these studies might be due to the general idea about smoking as the main risk factor for many types of cancer.

The early detection and diagnosis of $\mathrm{CC}$ can contribute to the reduction of its incidence $^{21}$. In this study more than half of women $57.6 \%$ knew that this cancer can be prevented $^{28}$. The same result $57.0 \%$ was reported in the South African ${ }^{29}$. In another study in India showed that more than two thirds of nursing staff $69 \%$ know that CC is a preventable disease ${ }^{30}$. This variation can be due to the increase and continuing educational programs regarding $\mathrm{CC}$ year after year.

The main source of information was friends or family members $71.6 \%$ in CC and $63.9 \%$ in PS, for more than half $57.2 \%$ and more than one third $36.0 \%$ of women heard about CC and PS respectively in this study, and it differed when compared with another study conducted in Kuwait which found that $76.9 \%$ of the women had heard about PS and the main source of information was the Gynecologist or family doctor $42.0 \% 17$, and other findings in developing countries such as Brazil which found that $81.0 \%$ of the women heard about PS ${ }^{31}$. The differences in the above studies could be due to the difference of populations involved and various levels of health intervention such as provided screening programs and the health education by the doctors or other health staff were successful in increasing knowledge of cervical cancer screening, PS, among lowincome country.

Regarding cure from $\mathrm{CC}$, there was a study in South Africa found that $15.0 \%$ of the respondents thought $\mathrm{CC}$ can't be cured, and more than one third $36.7 \%$ of women believed the same in a study in Cambodia $^{20}$. In this study, about half of women $47.6 \%$ believed that $\mathrm{CC}$ can be cured; more than one third of women $38.9 \%$ knew that PS can help to detect CC earlier, and about $90.3 \%$ of women agreed that the PS is successful in reducing the incidence and mortality of CC. This could be a signal of the presence of misunderstanding about $\mathrm{CC}$ in the community and an indication that the knowledge level in our community is low. Another study was conducted in Qatar by a group of researchers who found an approximately two thirds (62.4\%) of women knew that PS can help to detect CC earlier $^{25}$. And a study in Malaysia Mentioned more than two thirds $78.6 \%$ of university staff knew that the purpose of $\mathrm{PS}$ is to detect $\mathrm{CC}^{32}$.

The present study concluded that there is a significant association between women's knowledge of $\mathrm{CC}$ and age, gravidity, residency, level of education, family history of $\mathrm{CC}$, and SES. These findings were similar to another study in Nepal with the same associations ${ }^{18,17}$. But there was no significant association between knowledge about CC and residency ${ }^{33}$.

Therefore, improving the demand and availability of skilled maternity care can be a chance to provide information and increase the awareness of women about CC signs and symptoms, risk factors, prevention, and early detection. The media is a very important source of this information as well. Developing the policies for screening women, including perfect programs and projects by the related ministry will be very effective in 


KNOWLEDGE ABOUT CERVICAL
enhancing health promotion among
women.
The present study had the following
limitations: No previous (KAP) study
about CC was conducted in Duhok city,
and the sample population may potentially
limit the generalization of the findings;
further study is needed to assess the larger
samples of women and using random
sampling.

\section{CONCLUSIONS}

The majority of women had limited knowledge regarding $\mathrm{CC}$ and its risk factors. There was a significant association between CC knowledge and women's socio-demographic characteristics apart of residency. Nurses and care providers play an integral role in health promotion and education among women toward the prevention of the most diseases.

\section{REFERENCES}

1. Shah V, Vyas S, Singh A, Shrivastava M. Awareness and knowledge of cervical cancer and its prevention among the nursing staff of a tertiary health institute in Ahmedabad, Gujarat, India.Ecancermedicalscience. 2012; 6: 270.

2. Elfström KM, Herweijer E, Sundström K, Arnheim-Dahlström L. Current cervical cancer prevention strategies including cervical screening and prophylactic human papillomavirus vaccination: a review CurrOpinOncol 2014; 26 (1): 120129.

3. Bradford L, Goodman A. Cervical cancer screening and prevention in low-resource settings. ClinObstet Gynecol. 2013; 56(1): 76-87.

4. WHO. Sexual and reproductive health, 2012. Www.who.int/reproductive health/topics/cancers/en/ (accessed 16 April 2012).

5. Guidelines for cervical cancer screening. Government of India and WHO Collaborative Program. [Last accessed on 2012 Jan 23]. Available from:http://www.whoindia.org/ Link Files/ Cancer_ resource_ Guidelines_ for_CCSP.pdf .

6. Urasa M, DarjE. Knowledge of cervical cancer and screening practices of nurses at a regional hospital in Tanzania. Afr Health Sci. 2011; 11(1):48- 57.

7. CDC (HPV Vaccines). Centers for Disease Control and Prevention (CDC). Available from: http://www.cdc.gov/vaccines.

(Accessed: 26 July 2015).

8. Ferlay J, Soerjomataram I, Dikshit R, Eser S, Mathers C, Rebelo M, et al. Cancer incidence and mortality worldwide: sources, methods and major patterns in GLOBOCAN 2012. Int J Cancer. 2015; 136: E359E386. doi: 10.1002/ ijc.29210. [PubMed] [Cross Ref]

9. Iraqi Cancer Board (2012). Results of the Iraqi Cancer Registry 2011. Baghdad, Iraqi Cancer Registry Center, Ministry of Health.

10. Saadoon OZ, Amin RM, Jadoo SA. Factors influencing pap smear practice among primary school teachers in Diyala City, Iraq. MJPHM.2014; 14 (1):19-28.

11. Alwan N, Al-Attar W, Al Mallah N, Abdulla K. Assessing of Knowledge, 
Attitude and Practices towards

Cervical Cancer Screening among a sample of Iraqi Female population. Iraqi Journal of biotechnology. 2017; 16 (2): 38-47.

12. Al Shimmary I. and Al-Alwan N. (2007). Significance of Cervical Cytology (Pap smears) in the Detection of Precancerous Cervical Lesions. J. Fac. Med. Baghdad Univ., 49 (3): 315-322.

13. WHO/ ICO Information Centre on HPV and Cervical Cancer. HPV Information Centre. Human Papillomavirus and Related Cancers in Iraq. [2014 November 29]; http//:www.who.int/hpvcentre. 2014 [ Google Scholar].

14. Nahida A. Knowledge, Attitude and Practice on Dengue Fever. Thesis for Master Public Health. College of Public Health Sciences: Chulalongkorn University.

15. Osman MT, Red Hwan A. Al-Naggar and Balsam I. Taha. Knowledge and Awareness of Cervical Cancer Screening among Iraqi Immigrant Women Living in Malaysia. World Journal of MedicalSciences.2013; 8(2): 123-129.

16. Akujobi CN, Ikechebelu JI, Onunkwo I, Onyiaorah IV. Knowledge, attitude and practice of screening for cervical cancer among female students of a tertiary institution in South Eastern Nigeria. Niger J Clin Pract.2008; 11: 216-9

17. Al-Sairafi M, Mohamed FA. Knowledge, attitudes, and practices related to cervical cancer screening among Kuwaiti women. Med Princ Pract.2009; 18: (1) 35-42.
18. Shrestha J, Saha R, Tripathi N. Knowledge, Attitude and Practice regarding Cervical Cancer Screening Amongst Women visiting Tertiary Centre in Kathmandu, Nepal. Nepal J of Med Sci.2013; 2(2):85-90.

19. Roy B, Tang TS. Cervical cancer screening in Kolkata, India: beliefs and predictors of cervical cancer screening among women attending a women's health clinic in Kolkata, India. J Cancer Educ.2008; 23:253-9.

20. Sothy Touchand Jin-Kyoung Oh. Knowledge, attitudes, and practices toward cervical cancer prevention among women in Kampong Speu Province, Cambodia, BMC Cancer. 2018; 18: 294.

21. Alwan, N.; Al-Attar, W.; Eliessa, R.; AlMidfaei, Z. and Nidhal, F. (2012). Knowledge, Attitude and Practice regarding Breast Cancer and Breast Self-Examination among a Sample of the Educated Population in Iraq. Eastern Mediterranean Health Journal, WHO, EMRO, 18 (4): 337-345.

22. Harsha H N, Tanya S. A Study on Knowledge and Screening for Cervical Cancer among Women in Mangalore City. Ann Med HealthSci Res.2014;4(5):751-756.

23. Tchounga BK, Jaquet A, Coffee PA, Horo A,Sauvaget C, Adoubi I, et al. Cervical cancer prevention in reproductive health services: knowledge, attitudes and practices of midwives in Côte d'Ivoire, West Africa. BMC Health Services Research. 2014; 14:165.

24. Onsuz MF, Hidiroglu S, Sarioz A, Metintas S, Karavus M. Knowledge, Attitudes and Behaviors of Women 
Over 20 Years Old on Cervix Cancer in Istanbul, Turkey. Asian Pac J Cancer Prev.2014; 15(20): 8801-7.

25. Al-Meer FM, Aseel MT, Al-Khalaf J, Al-Kuwari MG, Ismail MFS. Knowledge, attitude and practices regarding cervical cancer and screening among women visiting primary health care in Qatar. EMHJ.2011; 17(11): 855-61.

26. Hwaid AH. Knowledge and Awareness of Papillomavirus and Cervical Cancer among College Students and Health Care Workers Women in Diyala, Iraq. AHPHR. 2013; 8: 221-225.

27. Ali SF, Ayub S, Manzoor NF, Azim S, Afif M, Akhtar Net al. Knowledge and awareness about cervical cancer and its prevention amongst interns and nursing staff in Tertiary Care Hospitals in Karachi, Pakistan. 2010; 5(6): e11059

28. Adams EK, Breen N. Joski P J, Impact of the National Breast and Cervical Cancer Early Detection Program on mammography and pap test utilization among white, Hispanic, and African American women: 1996-2000. Cancer.2007; 109: 348-358.

29. Hoque M, Hoque E, Kader SB. Evaluation of cervical cancer screening program at a rural community of South Africa. East Afr J Public Health. 2008; 5(2):111-6.

30. Goyal A, Vaishnav G, Shrivastava A, Verma R, Modi A. Knowledge, Attitude and practices about cervical cancer and screening among nursing staff in a teaching hospital. Int $\mathbf{J}$ Med Sci Public Health. 2013; 2: 249-53.

31. Moreira ED Jr, Oliveira BG, Ferraz FM, Costa S, Costa Filho JO, Karic G. Knowledge and Attitudes about human papillomavirus, Pap smears, and cervical cancer among young women in Brazil: implications for health education and prevention. Int $\mathbf{J}$ Gynecol Cancer. 2006 ;16:599-603.

32. Al-Naggar RA, Chen R. Practice and Barriers towards Cervical Cancer Screening Among University Staff at a Malaysian University. J Community Med Health Edu.2012; 2(1):1-7.

33. Gamaarra CJ, Valente JG, Silva GA . Correction for reported cervical cancer mortality data in Brazil 1996-2005. Rev Saude Publica.2010; 44:629-38. 


\section{بوخته}

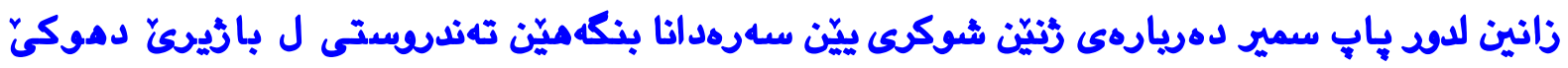
دكهن

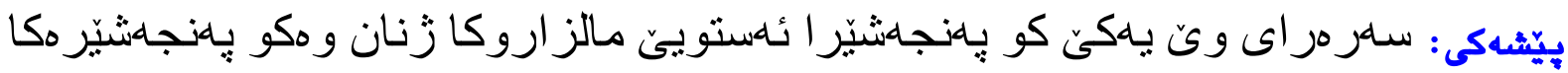

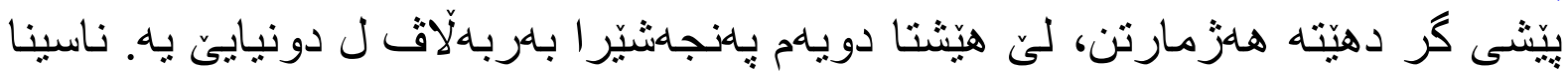

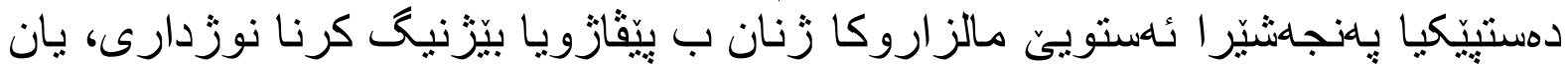
باب سمير (Pap smear) دهيّته كرن.

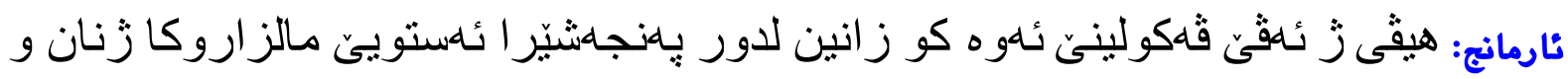

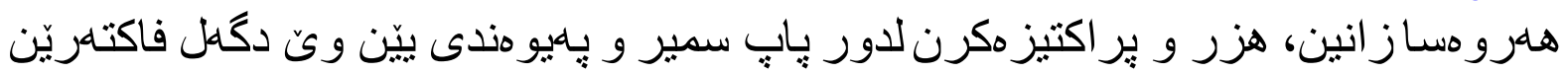

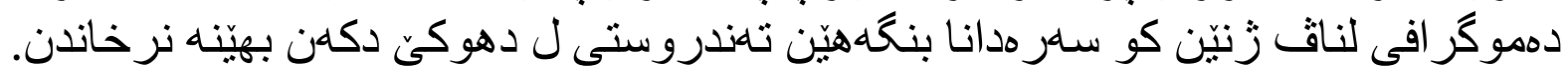

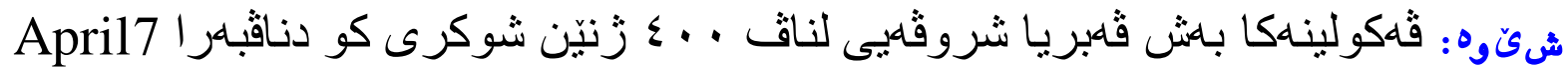

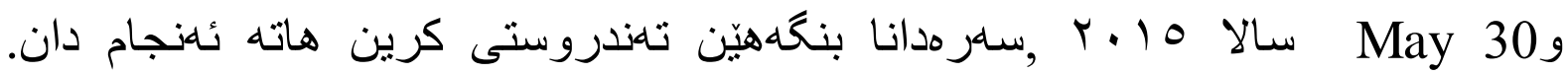

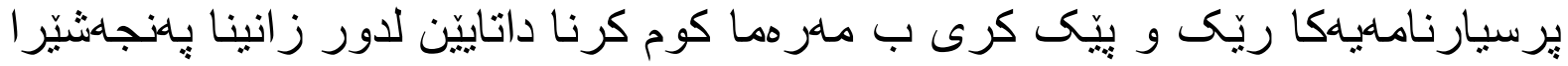

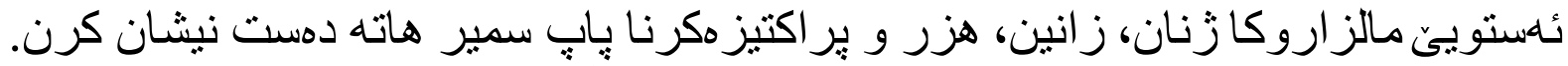

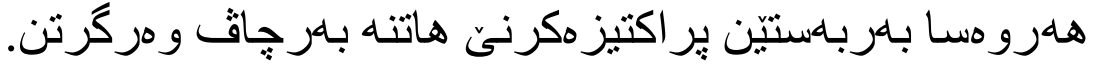

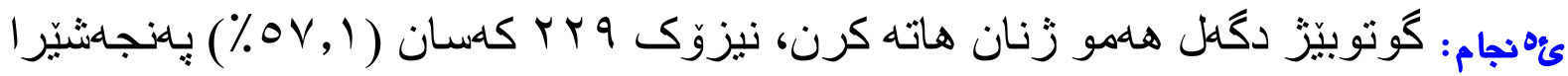

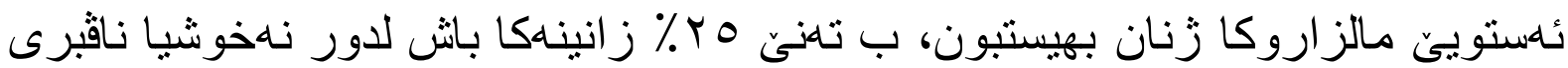

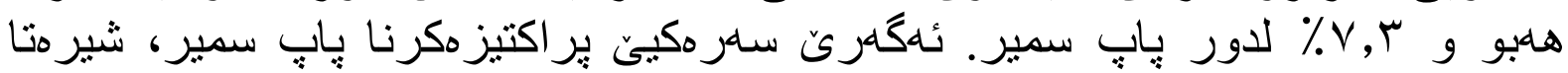

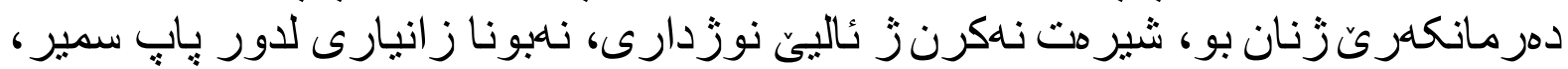

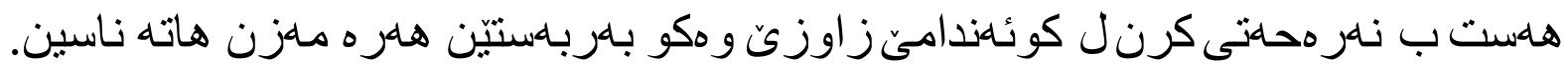

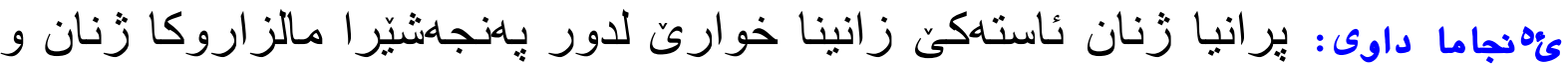

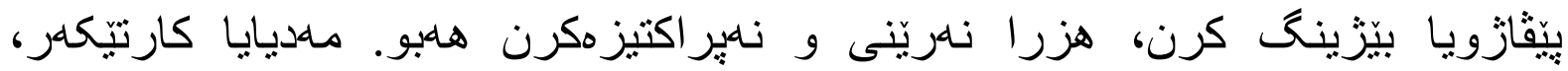

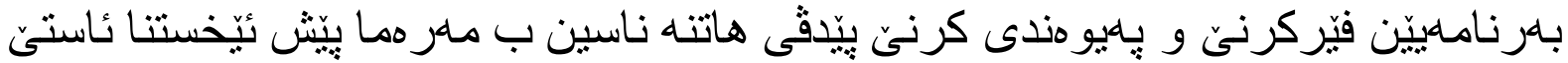

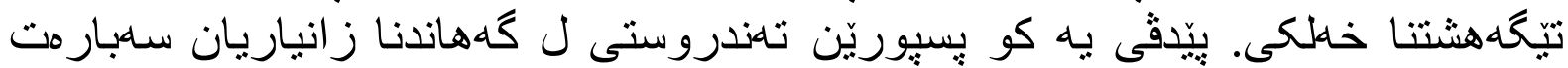

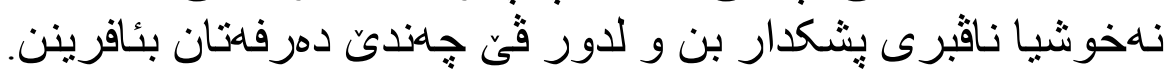




\section{الخلاصة}

المعارف حول مسحة عنق الرحم بين النساء المتزوجات اللواتي يراجعن مراكز العناية الصحية الأولية في مدينة دهوك

الخلفية: على الرغم من الاعتبار أن سرطان عنق الرحم هو من السرطانات التي يمكن الوقاية منها،

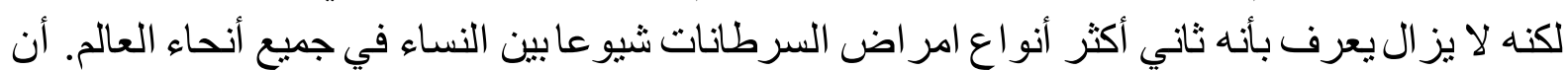

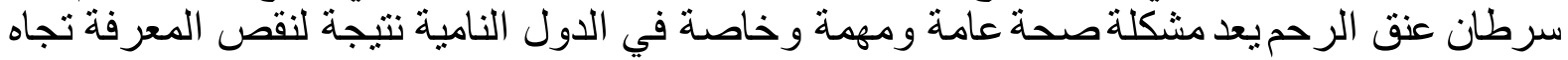
هذا المرض وضلة المعلومات فيما يخص عو امل الخطورة وكيفية الوقاية منه, ويتم الكثف المبكة المبكر عن طريق إجراء فحص الطبي بدعى (مسحة البحن عنق الرحم).

الأهداف: هدفت هذه الدراسة إلى تقييم المعرفة عن سرطان عنق الرحم و المعارف حول مسحة عنق الرحم وارتباطه مع الخصائص الديموغر افية بين النساء اللواتي يرتدن مر اكز الرعاية الصحية الأولية في مدينة دهو ك.

الأساليب: أجريت در اسة وصفية مقطعية على 400 امر أة في وقت جمع البيانات من 7 نبسان - 30أيار 2015. وتم جمع المعلومات عن طريق استبيان منظم لجمع البيانات المتعلقة بالمعارف حول سرطان الرئ عنق الرحم ومسحة عنق الرحم.

النتيجة: من بين كل النساء اللواتي تم مقابلتهم، حوالي 57.2\% سمعوا عن سرطان عنق الرحم، و35.9\% سمعو ا عن مسحة عنق الرحم. فقط الربع 25\% من النساء لديهم معرفة جيدة عن سرطان عنق

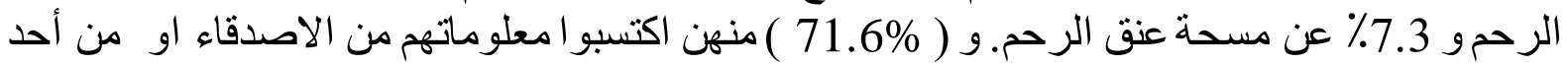
افر اد العائلة المصابين, و $6.5 \%$ منهن فقط كانت معلوماتهم من التلفاز ومن وسائط الانترنيت.

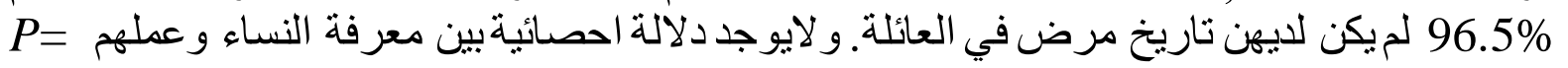

الخلاصة: كانت غالبية النساء لديهن معرفة منخفضة عن سرطان عنق الرحم ومسحة عنق الرحم, و أن

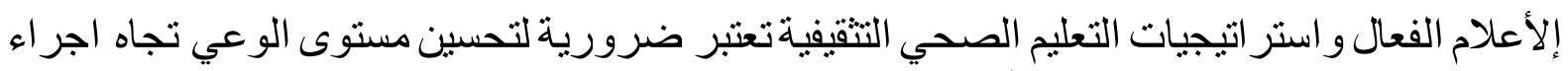

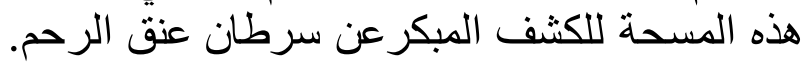

